\title{
The expression of miRNA encoded by C19MC and miR-371-3 strongly varies among individual placentas but does not differ between spontaneous and induced abortions
}

\author{
Andrea Gottlieb ${ }^{1}$ (D) - Inga Flor ${ }^{1} \cdot$ Rolf Nimzyk $^{1} \cdot$ Lars Burchardt $^{1} \cdot$ Burkhard Helmke $^{2} \cdot$ Marc Langenbuch $^{3}$. \\ Meike Spiekermann $^{1}$ • Susanne Feidicker ${ }^{4,5}$ • Jörn Bullerdiek ${ }^{1,6}$ (D)
}

Received: 19 July 2020 / Accepted: 24 August 2020 / Published online: 9 October 2020

(C) The Author(s) 2020

\begin{abstract}
miRNAs of the largest human miRNA gene cluster at all, i.e., C19MC, are almost exclusively expressed in the placenta. Nevertheless, only little is known about the interindividual variation of their expression and even about possible influence of gestational age, conflicting data is reported as well as for miRNAs of the much smaller miR-371-3 cluster. Our present study aims at the analyses of the expression of miRNAs from both clusters at different times of pregnancy, possible differences between placenta samples obtained from spontaneous or induced abortions in the first trimester, and the possible variation of miRNA expression at different sites within same placentas. miR-371a-3p, miR-372-3p, miR-373-3p, miR-517a-3p, and miR-520c-3p were quantified in 85 samples and miR-371a-3p was quantified in maternal serum samples taken immediately before delivery. While for miRNA-517a-3p and miR-520c-3p the expression increased with increasing gestational age, the present study revealed strong interindividual differences in the expression of miR-371-3 in full-term placental tissue as well as for miRNAs of the C19MC cluster, where the levels differed to a much lesser extent than for the former microRNAs. Also, strong interindividual differences were noted between the serum samples but differences related to the site of the placenta where the sample has been taken from were excluded. For neither of the data from placental tissue, the study revealed differences between the spontaneous and induced abortion group. Thus, the differences do not in general seem to be related to first trimester abortion. It remains to be elucidated whether or not they affect other prenatal processes.
\end{abstract}

Keywords microRNA $\cdot \mathrm{C} 19 \mathrm{MC} \cdot \mathrm{miR}-371-3 \cdot$ Placenta $\cdot$ Sampling site $\cdot$ Abortion

Andrea Gottlieb and Inga Flor contributed equally to this work.

Handling Editor: Reimer Stick

Electronic supplementary material The online version of this article (https://doi.org/10.1007/s00709-020-01548-3) contains supplementary material, which is available to authorized users.

Jörn Bullerdiek

bullerd@uni-bremen.de

1 Center of Human Genetics, University of Bremen, Leobener Strasse 2, 28359 Bremen, Germany

2 Institute for Pathology, Elbe Clinic Stade-Buxtehude, Bremervörder Strasse 111, 21682 Stade, Germany

3 Clinic of Gynecology and Obstetrics, Helios Clinic, Altenwalder Chaussee 10, 27474 Cuxhaven, Germany
4 Department of Gynecology and Obstetrics, Evang. Diakonie-Hospital, Gröpelinger Heerstrasse 406-408, 28239 Bremen, Germany

5 Department of Obstetrics and Gynecology, University Hospital Frankfurt, Theodor-Stern Kai 7, 60590 Frankfurt am Main, Germany

6 Institute for Medical Genetics, University of Rostock, University Medicine, Ernst-Heydemann-Strasse 8, 18057 Rostock, Germany 


$\begin{array}{ll}\text { Abbreviations } \\ \text { AR } & \text { Induced abortions } \\ \text { B4GALT3 } & \beta \text {-1,4-Galactosyltransferase III } \\ \text { C19MC } & \text { Chromosome 19 microRNA cluster } \\ \text { FFPE } & \text { Formalin-fixed paraffin-embedded } \\ \text { GA } & \text { Gestational age } \\ \text { MSA } & \begin{array}{l}\text { Spontaneous abortions, including } \\ \text { missed abortions }\end{array} \\ \text { RT } & \text { Reverse transcription } \\ \text { RM } & \text { Recurrent miscarriage } \\ \text { TE } & \text { Full-term placentas }\end{array}$

\section{Introduction}

Chromosome 19 microRNA cluster (C19MC) is primate specific and encodes more than 50 mature miRNAs (Bentwich et al. 2005; Bortolin-Cavaillé et al. 2009). As to its presumed evolution, this large cluster has emerged in a relatively short period of time from a preexisting much smaller cluster (miR371-3) orthologous of which can be detected in all mammalian species (e.g., mmu-mir-290-295 in mice and rno-mir-290295 in rat) (miRBase 2014; Zhang et al. 2008). Compared with the size of C19MC, little is known about its function. Accordingly, the functions of the corresponding human predecessor cluster miR-371-3 encoding only six mature miRNAs have been elucidated not fully so far. The expression of both clusters is limited to only a few tissues mainly of the embryonic and fetal period of life and C19MC. Apparently, with few exceptions, its expression is almost exclusively restricted to a few extraembryonic tissues as in particular the placenta. In line with these findings, abundant expression of miRNAs of this latter cluster can be noted in tumors derived from these tissues and cell lines derived thereof, respectively (Morales-Prieto et al. 2012), (Strub et al. 2016). In contrast, transcriptional re-awakening in thyroid adenomas seems to be due to rearrangements of transcriptional activators juxtaposed to the gene cluster (Rippe et al. 2010). Formerly, it was thought that its expression is even restricted to the trophoblast but then C19MC-derived miRNAs were also detected in the mesenchymal core of chorionic villi and in the mesenchyme of the amniotic membrane (Flor et al. 2012). miRNAs of this cluster constitute the major part of the miRNA cargo of placental exosomes suggesting that they serve important functions not only in their cells of origin but also in recipient cells of the released exosomes as in particular maternal NK cells (Donker et al. 2012; Ishida et al. 2015; Kambe et al. 2014). One important mechanism seems to be influencing the immune response against viral infections as demonstrated by Delorme-Axford et al. (2013) in a series of experiments. The authors found that placental trophoblast cells are highly resistant to several virus infections and additionally confer their resistance to other nonplacental cells via exosomes containing, among others, specific miRNAs of C19MC. Furthermore, immunomodulatory functions related to the establishment and maintenance of embryo-maternal tolerance have also been assumed to be influenced by these miRNAs (Bullerdiek and Flor 2012; Ishida et al. 2015; Kambe et al. 2014). In addition, there is an increasing evidence that contribution to proper implantation and placenta development is another group of functions addressed by the miRNAs of both clusters (Xie et al. 2014). Accordingly, a comparison of the placental miRNAome between human and macaque revealed conserved expression of miRNAs of the C19MC and miR371-3 clusters, thus indicating similar functions of miRNAs of both clusters for placentation in nonhuman primates as well (Schmidt et al. 2018). Nevertheless, given the variety of miRNAs encoded by C19MC alone as well as the differences of the seed sequences, it is tempting to assume that the majority of functions of these miRNAs still remain to be fully elucidated (for review, see Malnou et al. 2019). Furthermore, conflicting data exists as for their expression at different time points during pregnancy (Gu et al. 2013; Morales-Prieto et al. 2012). On the other hand, the question if this may be due to different sampling procedures and the position of the sample within the placenta has not been addressed in detail. Therefore, our present study aims at the analyses of the expression of representative miRNAs from both clusters at different times of pregnancy, possible differences between placenta samples obtained from spontaneous or induced abortions in the first trimester, and the possible variation of miRNA expression at different sites within the same placentas. We feel that such study is still missing and its results may help to understand the functions of these miRNAs.

\section{Materials and methods}

\section{Tissue samples}

To assure comparability of the results, all investigations were performed on formalin-fixed paraffin-embedded (FFPE) samples (see e.g. Noack et al. 2011) and accordingly fresh samples as well were subjected to the FFPE procedure prior to isolation of RNA. Placenta samples of induced and spontaneous abortions (GA week 7-33) were retrieved from the archive and comprised cases from 2010 to 2014. Pathological examinations were performed after hematoxylin and eosin staining of the samples for diagnostic purposes. Full-term placental tissue was collected after timely delivery (estimated date \pm 2 weeks). Placental samples of women suffering from preeclampsia were excluded. In case of full-term placentas, a randomly sampled piece of placenta was transferred to $4 \%$ buffered formalin immediately after delivery followed by paraffin embedding according to standard techniques. 
In addition, six samples of three full-term placentas each were obtained from defined sample sites in two depths (A, B, C: chorion plate; D, E, F about $2 \mathrm{~cm}$ closer to basal plate) to prove if the collection site has an influence on expression levels. Amniotic membrane was removed before sampling. The sampling points were A and D, near the umbilical cord; $\mathrm{B}$ and $\mathrm{E}$, the middle distance between the umbilical cord and the marginal sinus; and $\mathrm{C}$ and $\mathrm{F}$, near the marginal sinus. Samples were transferred to $4 \%$ buffered formalin immediately and further processed to FFPE samples.

In total, FFPE tissue samples from 85 placentas were examined. These comprised 23 induced abortions (AR), 39 spontaneous abortions (MSA, including missed abortions), and 23 full-term placentas (TE). Three additional full-term placentas were investigated for the analysis of possible influences of the collection site.

\section{Serum samples}

Serum was collected from women shortly before timely delivery (estimated date \pm 2 weeks). Blood was centrifuged at $2700 \times \mathrm{g}$ for $10 \mathrm{~min}$ within $30 \mathrm{~min}$ after collection. Serum aliquots were transferred into cryotubes and immediately stored at $-34{ }^{\circ} \mathrm{C}$ for 5 to 30 days. Subsequently, the serum samples were frozen at $-80{ }^{\circ} \mathrm{C}$ before further processing.

\section{RNA isolation}

For RNA isolation, six to twelve tissue sections from FFPE samples of $5 \mu \mathrm{m}$ each were used. Total RNA isolation was performed using the innuPREP Micro RNA Kit (Analytik Jena AG, Jena, Germany) according to the manufacturer's instructions with the following modifications: lysis of the paraffin sections preceding RNA isolation was conducted using TLS-Lysis Solution and Proteinase K from the innuPREP DNA Micro Kit (Analytik Jena AG) without prior deparaffinization. Sections were incubated for $1 \mathrm{~h}$ at $60{ }^{\circ} \mathrm{C}$ and $15 \mathrm{~min}$ at $80{ }^{\circ} \mathrm{C}$.

For RNA isolation from serum samples $200 \mu \mathrm{l}$ of serum was thawed on ice. Total RNA was extracted using the miRNeasy Mini Kit (Qiagen, Hilden, Germany) according to the manufacturer's instructions with one minor modification: $400 \mu \mathrm{l}$ of the aqueous phase were mixed with $600 \mu \mathrm{l}$ of ethanol.

\section{Reverse transcription}

To quantify the expression of miR-371a-3p, miR-372-3p, miR-373-3p, miR-517a-3p, and miR-520c-3p in FFPE samples and of miR-371a-3p in serum samples, miRNAs were reverse-transcribed into cDNA using the TaqMan microRNA RT kit (Applied Biosystems, Darmstadt,
Germany). Of the total RNA of each FFPE sample, $200 \mathrm{ng}$ were used for reverse transcription, whereas $55 \mathrm{ng}$ of total serum RNA were used. Specific miRNA stem loop primers (Applied Biosystems, Darmstadt, Germany) were used (assay numbers: 371a-3p: 002124; 372-3p:000560; 373-3p: 000561; 517a-3p: 002402; 520c-3p: 002402; RNU6B: 001093, 20a: 000580). For serum samples, a primer pool consisting of $0.75 \mu \mathrm{l}$ each of stem loop primer miR-371a-3p and miR-20a-3p (as an endogenous control) was used. For each sample, a negative control (-RT) was measured and for each microRNA a non-template control was included. The reactions with a final volume of $15 \mu \mathrm{l}$ were incubated in a thermal cycler (Biometra TGradient or Biometra Trio-Thermoblock, or, for serum samples, GeneAmp PCR-System 2700 (Applied Biosystems)) for $30 \mathrm{~min}$ at $16{ }^{\circ} \mathrm{C}, 30 \mathrm{~min}$ at $42^{\circ} \mathrm{C}$, and $5 \mathrm{~min}$ at $85^{\circ} \mathrm{C}$, respectively. Samples were stored at $4{ }^{\circ} \mathrm{C}$ for immediate qRT-PCR or at $-20^{\circ} \mathrm{C}$ for later processing.

\section{Pre-amplification of RT products in serum samples}

Of miRNA-371a-3p and miRNA-20a-3p assay, $0.75 \mu$ were diluted in a $13.5-\mu$ l nuclease-free water. The PCR with a final volume of $50 \mu \mathrm{l}(12.5 \mu \mathrm{l}$ of this solution, $12.5 \mu \mathrm{l}$ of RT product, $25 \mu \mathrm{l}$ TaqMan Universal PCR Master Mix (Applied Biosystems)) was performed at $95{ }^{\circ} \mathrm{C}$ for $10 \mathrm{~min}$, followed by 14 cycles of $95^{\circ} \mathrm{C}$ for $15 \mathrm{~s}$ and $60^{\circ} \mathrm{C}$ for $4 \mathrm{~min}$ using the GeneAmp PCR-System 2700 (Applied Biosystems). The pre-amplification product was diluted 1:5 in nuclease-free water.

\section{Real-time PCR}

Real-time PCR was performed using the Applied Biosystems sequence detection system 7300 (Applied Biosystems, Darmstadt, Germany) in 96-well microtiter plates with a total volume of $20 \mu \mathrm{l}$. Each reaction of FFPE sample cDNA consisted of 7.67- $\mu$ l nuclease-free water, 10- $\mu$ l TaqMan Universal Master Mix, 1- $\mu$ l TaqMan microRNA assay, and 1.33- $\mu$ l probe. Each reaction of serum cDNA consisted of $9 \mu 1$ of the pre-amplification product, 10- $\mu$ l TaqMan Universal PCR Master Mix, and 1- $\mu$ l TaqMan microRNA assay. For each sample, PCR was performed in triplicate and one negative control was run. Non-template controls of cDNA and PCR of each miRNA were run on every plate. PCR conditions were $50{ }^{\circ} \mathrm{C}$ for $2 \mathrm{~min}$, followed by $95^{\circ} \mathrm{C}$ for $10 \mathrm{~min}$ and 40 (serum) or 50 (FFPE) cycles of $15 \mathrm{~s}$ at $95^{\circ} \mathrm{C}$ and $1 \mathrm{~min}$ at $60{ }^{\circ} \mathrm{C}$.

Relative quantification was performed using the ddCT method (Livak and Schmittgen 2001). For FFPE samples, a thyroid tumor with $19 \mathrm{q} 13$ rearrangement known to overexpress C19MC and miR-371-3 (S958) served as a positive control. Another thyroid tumor without $19 \mathrm{q} 13$ 
rearrangement and therefore with low expression in both miRNA clusters (S925) was used as a calibrator as described in Flor et al. (2012). In FFPE samples, RNU6B served as endogenous control for normalization according to Luo et al. (2009), Donker et al. (2012), Flor et al. (2012), Gu et al. (2013), and others. For serum samples, miR-20a served as an endogenous control as suggested by Gillis et al. (2013).

\section{Statistical analysis}

The two-sided Wilcoxon signed-rank test was used to compare averages from two groups. The Kruskal-Wallis test was used when more than two groups were compared. Relationships between two observed or measured amounts were quantified by linear regression. A $p$ value of less than 0.05 was considered being significant, a $p$ value of less than 0.001 was termed "highly significant." Statistical calculations were done using the $\mathrm{R}$ package, version 3.2.3 (R Core Team 2015).

\section{Results}

\section{miRNA expression levels differ within a broad range}

In eighty-five placentas, the concentration of representative miRNAs of the two neighboring clusters C19MC and miR371-3 was measured. These were miRNA 371a-3p, 372-3p, $373-3 p, 517 a-3 p$, and 520c-3p. The samples belonged to either of three subgroups: 23 were placentas collected after timely delivery (TE) (gestational age (GA) 38-42), 23 were induced abortions (AR) (GA 7-13), and 39 were spontaneous abortions (MSA) (GA 7-33) (S1 Table).

First, we analyzed expression levels in full-term placentas, presenting with only a small variety of their GA. Expression was largely different in the investigated miRNAs with low expression of miR-373-3p (median RQ of full-term placentas $=52.5$ ) ; middle expression of miR371a-3p (median RQ of full-term placentas: 2300), miR372-3p (median RQ of full-term placentas: 2697), and miR-520c-3p (median RQ of full-term placentas: 9182); and extremely high expression of miR-517a-3p (median RQ of full-term placentas: 133,200). All five miRNAs analyzed showed a wide expression range with the largest amplitude from lowest to highest expression in miR-371-3 and smaller amplitudes in miR-517a-3p and miR-520c-3p, respectively (Table 1 ). As the next step, we analyzed the expression levels in induced and spontaneous abortions. The wide expression range observed in full-term placentas was confirmed in both subgroups of abortions as well (Table 1).

\section{Expression levels do not obviously depend on sampling site}

In our experiments as well as in those described in the literature, the expression level of the miRNAs varied over a broad range and it seemed reasonable to assume that the site where the sample has been taken can influence the results. Thus, to check how the expression varies between different sampling sites and if the broad range in the expression might be determined by sampling site, we have used three additional full-term placentas where six samples each were taken at defined sites. The measurement of all five miRNAs in a total of these 18 samples did not show an obvious influence of the collection site but the individual differences in expression between the three placentas (Fig. 1, S1 Fig.). Accordingly, no differences in expression between means of the six sampling sites and 23 randomly sampled full-term placentas were detected by the Wilcoxon signed-rank test (miR-371a-3p, $p=0.7046$; miR-372-3p, $p=1$; miR-373-3p, $p=0.7046$; miR-517a-3p, $p=0.4415$; miR-520c-3p, $p=0.0785$ ).

\section{Expression of miR-517a-3p and miR-520c-3p increases significantly with the progression of pregnancy}

Concerning the change in expression from first to third trimester, conflicting results have been published. Morales-Prieto et al. (2012) found an increasing expression in miRNAs of the C19MC cluster in the first and third trimester trophoblast cells, whereas no significant changes were observed in miR-371-3. On the other hand, $\mathrm{Gu}$ et al. (2013) found a decreasing expression of miR371-3 and miR-520c and unchanged expression of miR$517 \mathrm{a}$ in the first compared with the third trimester placental tissue. To check if and how the expression in the placental tissue changes with progression of pregnancy, we next analyzed the expression patterns of the abovementioned miRNAs as a function of GA. The analysis focused on gestational week without stratification in induced and spontaneous abortion.

Due to multiple testing, a Bonferroni correction was made resulting in $\alpha=0.01$. Linear regression analysis revealed a highly significant increase from the first to the third trimester of miR-517a-3p ( $p=0.000003$, fold change: 3.9) and miR-520c-3p ( $p=0.000001$, fold change: 3.4 ). These differences were also noted when comparing samples derived from term placentas with those from induced abortions alone (Fig. 2). In contrast, no significant differences in expression could be observed in different stages of pregnancy in miR-371a-3p ( $p=0.3905$, fold change: 2.0$)$; miR-372-3p ( $p=0.1474$, fold change: 2.2$)$, and miR-3733 p ( $p=0.018$, fold change:3.0) (Fig. 2). 
Table 1 Relative quantification of miRNA expression (fold change) in subsets of placenta samples

\begin{tabular}{|c|c|c|c|c|}
\hline \multirow[b]{2}{*}{ miRNA } & \multicolumn{4}{|c|}{ Type of abortion or delivery } \\
\hline & All & $\mathrm{AR}$ & MSA & TE \\
\hline 371a-3p & $n=85$ & $n=23$ & $n=39$ & $\mathrm{n}=23$ \\
\hline Median & 1521 & 1774 & 1193 & 2300 \\
\hline Mean & 2436 & 2413 & 1636 & 3814 \\
\hline SD & 3002 & 3006 & 1832 & 4056 \\
\hline Range & $52.9-15,980$ & $140.7-14,900$ & $52.9-10,720$ & $111.7-15,980$ \\
\hline$n$-fold $\max / \min$ & 302 & 106 & 203 & 143 \\
\hline $372-3 p$ & $n=85$ & $n=23$ & $n=39$ & $n=23$ \\
\hline Median & 1334 & 1156 & 984 & 2697 \\
\hline Mean & 2013 & 1631 & 1448 & 3354 \\
\hline SD & 2404 & 2022 & 1762 & 3164 \\
\hline Range & $45.2-11,890$ & $92.9-10,020$ & $45.2-10,450$ & $113.4-11,890$ \\
\hline$n$-fold $\max / \min$ & 263 & 108 & 231 & 105 \\
\hline 373-3p & $n=84$ & $n=22$ & $n=39$ & $n=23$ \\
\hline Median & 33.28 & 37.2 & 29.8 & 52.5 \\
\hline Mean & 64.6 & 51.4 & 35.6 & 126.4 \\
\hline SD & 104 & 60 & 35 & 173 \\
\hline Range & $1.8-713.9$ & $3.2-299.7$ & $1.8-218.1$ & $6.3-713.9$ \\
\hline$n$-fold $\max / \min$ & 397 & 93 & 124 & 113 \\
\hline $517 a-3 p$ & $n=65$ & $n=23$ & $n=19$ & $n=23$ \\
\hline Median & 52,080 & 36,800 & 44,850 & 133,200 \\
\hline Mean & 94,800 & 39,330 & 54,910 & 183,200 \\
\hline SD & 115,809 & 27,281 & 42,704 & 154,979 \\
\hline Range & $1940-481,300$ & $2250-119,400$ & $1940-160,400$ & $25,790-481,300$ \\
\hline$n$-fold $\max / \mathrm{min}$ & 248 & 53 & 83 & 19 \\
\hline $520 c-3 p$ & $n=84$ & $n=22$ & $n=39$ & $n=23$ \\
\hline Median & 4540 & 4472 & 3224 & 9182 \\
\hline Mean & 7387 & 5149 & 4111 & 15,080 \\
\hline SD & 9260 & 3045 & 2596 & 14,734 \\
\hline Range & $285.6-49,960$ & $1664-13,840$ & $285.6-13,060$ & $2453-49,960$ \\
\hline$n$-fold $\max / \min$ & 175 & 8 & 46 & 20 \\
\hline
\end{tabular}

AR: induced abortion; MSA: spontaneous abortion; TE: delivery at term +-2 weeks; SD: standard deviation; $n$ fold $\mathrm{max} / \mathrm{min}$ : ratio of highest expression divided by lowest expression

\section{No differences in expression of induced and spontaneous first trimester abortions were observed}

Since miRNAs of the C19MC cluster play a role in viral resistance (Delorme-Axford et al. 2013) and are also suspected to have immunomodulatory functions (Bullerdiek and Flor 2012) and since the miR-371-3 cluster is suspected to be involved in feto-maternal cross talk as well (Rosenbluth et al. 2014; Wang et al. 2016), we were interested to see if variations in the expression of these miRNAs might partly explain miscarriage events. We therefore analyzed the expression levels of induced and spontaneous first trimester abortions separately. The Wilcoxon signed-rank test showed no significant differences in expression of induced compared with spontaneous first trimester abortions in each of the investigated miRNAs (Table 2).

\section{miRNA concentration of miR-371a-3p in serum samples differs interindividually}

The unexpected finding of the wide expression range in placentas prompted us to see if this could be observed in serum as well.
While in the literature this variation has been well documented for miRNAs of the C19MC cluster (e.g., Mouillet et al. 2010), less data is available about the presence of miRNAs of the miR371-3 cluster. Therefore, the concentration of miR-371a-3p, the miRNA showing the widest expression range in full-term placental FFPEs, was measured in four serum samples taken shortly prior to timely delivery. Also in these samples, concentration differed individually, though in a range as half as wide compared with FFPE. The sample displaying the highest CT served as a calibrator. The other three samples showed RQ levels of 14.6, 21.8 , and 77.3 , respectively.

\section{Discussion}

C19MC is nearly exclusively expressed in the placenta (Bentwich et al. 2005; Luo et al. 2009), suggesting an important role in placental development and function. Specific function and regulation of C19MC in the placenta is not completely clear yet (reviewed by (Mouillet et al. 2015)), but three functional complexes are likely to be influenced by C19MC: these are viral resistance (Delorme-Axford et al. 2013), 

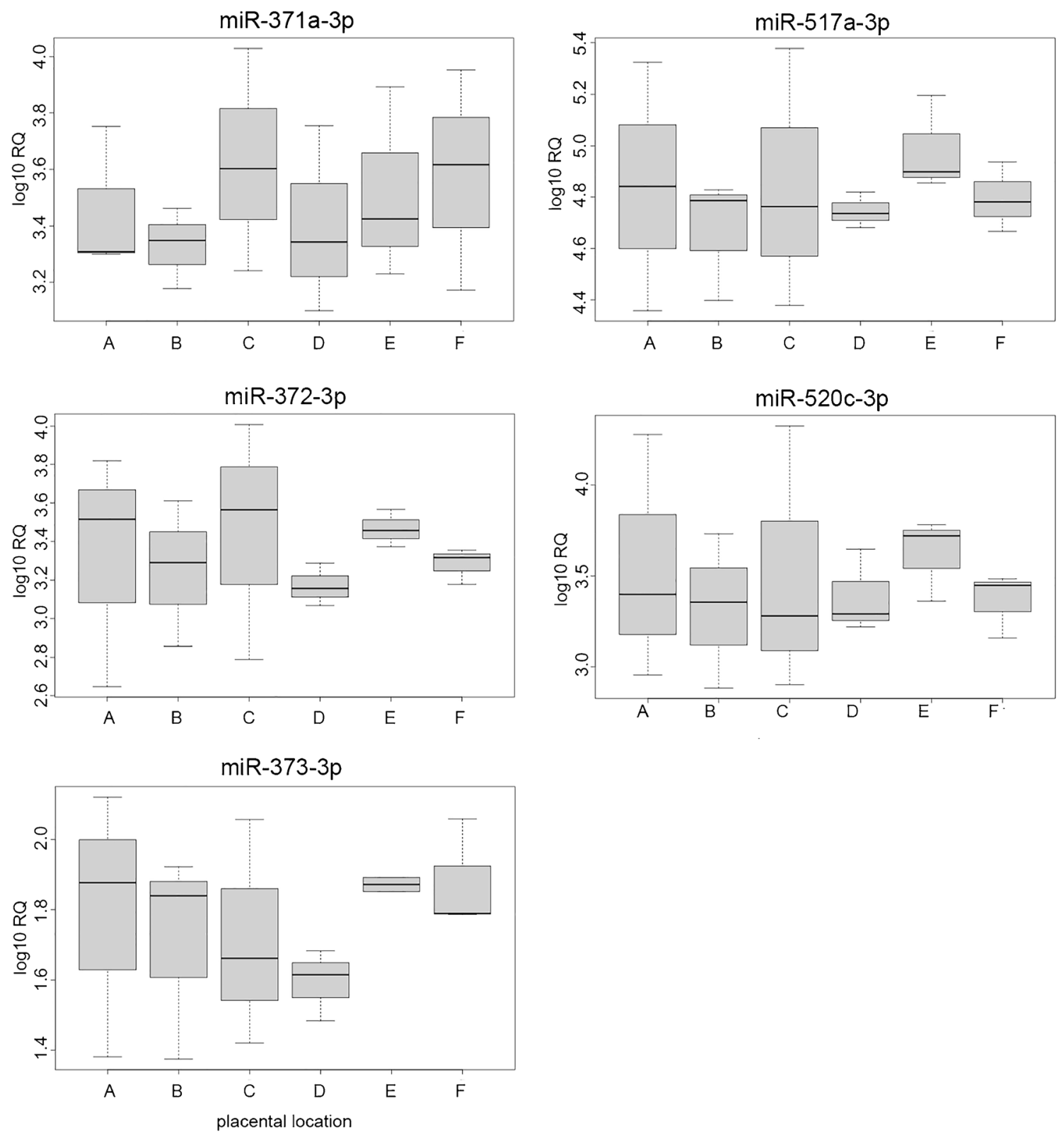

Fig. 1 Boxplots showing miRNA expression in six sampling sites of three placentas. $\mathrm{A}=$ chorion plate, near umbilical cord; $\mathrm{B}=$ chorion plate, middle distance between umbilical cord and marginal sinus; $\mathrm{C}=$ chorion plate, near marginal sinus; $\mathrm{D}=2 \mathrm{~cm}$ closer to basal plate, near umbilical cord; $\mathrm{E}=2 \mathrm{~cm}$ closer to basal plate, middle distance between umbilical cord and marginal sinus; $F=2 \mathrm{~cm}$ closer to basal plate, near

implantation and placenta development (Anton et al. 2015; Ding et al. 2015; Xie et al. 2014), and immunomodulation in terms of fetal-maternal cross talk (Bullerdiek and Flor 2012; Ishida et al. 2015; Kambe et al. 2014).

This is, to our knowledge, the first report investigating the expression of C19MC miRNAs and miR-371-3 cluster in the placental tissue comparing three groups (induced and spontaneous abortions and full-term placentas) in a large cohort. MiR-517a-3p and miR-520c-3p represented the placentaspecific C19MC. The miR-371-3 cluster was chosen because

marginal sinus. The Kruskal-Wallis analysis of variance showed no significant differences in expression between six sampling sites (miR-371a$3 \mathrm{p}: p=0.9369$, miR-372-3p: $p=0.6265$, miR-373-3p: $p=0.6788, \mathrm{miR}-$ 517a-3p: $p=0.6159$, miR-520c-3p: $p=0.8767$ ). Boxes contain the central $50 \%$ of values, lines inside boxes denote the median, whiskers extend to the extreme values or to $1.5^{*}$ box height, whatever is smaller

of its suspected role in stem cell maintenance (Langroudi et al. 2015) and cell differentiation (Kim et al. 2011), pointing at its possible role in trophoblast differentiation.

Overall, individual expression levels differed remarkably within each group (induced and spontaneous abortions and full-term placentas) for each of the five miRNAs investigated. In contrast, $\mathrm{Gu}$ et al. (2013) found relatively homogenous expression in six first and six third trimester placental tissues using microarray analysis. Our finding prompted us to examine if expression levels are dependent on sampling site. 

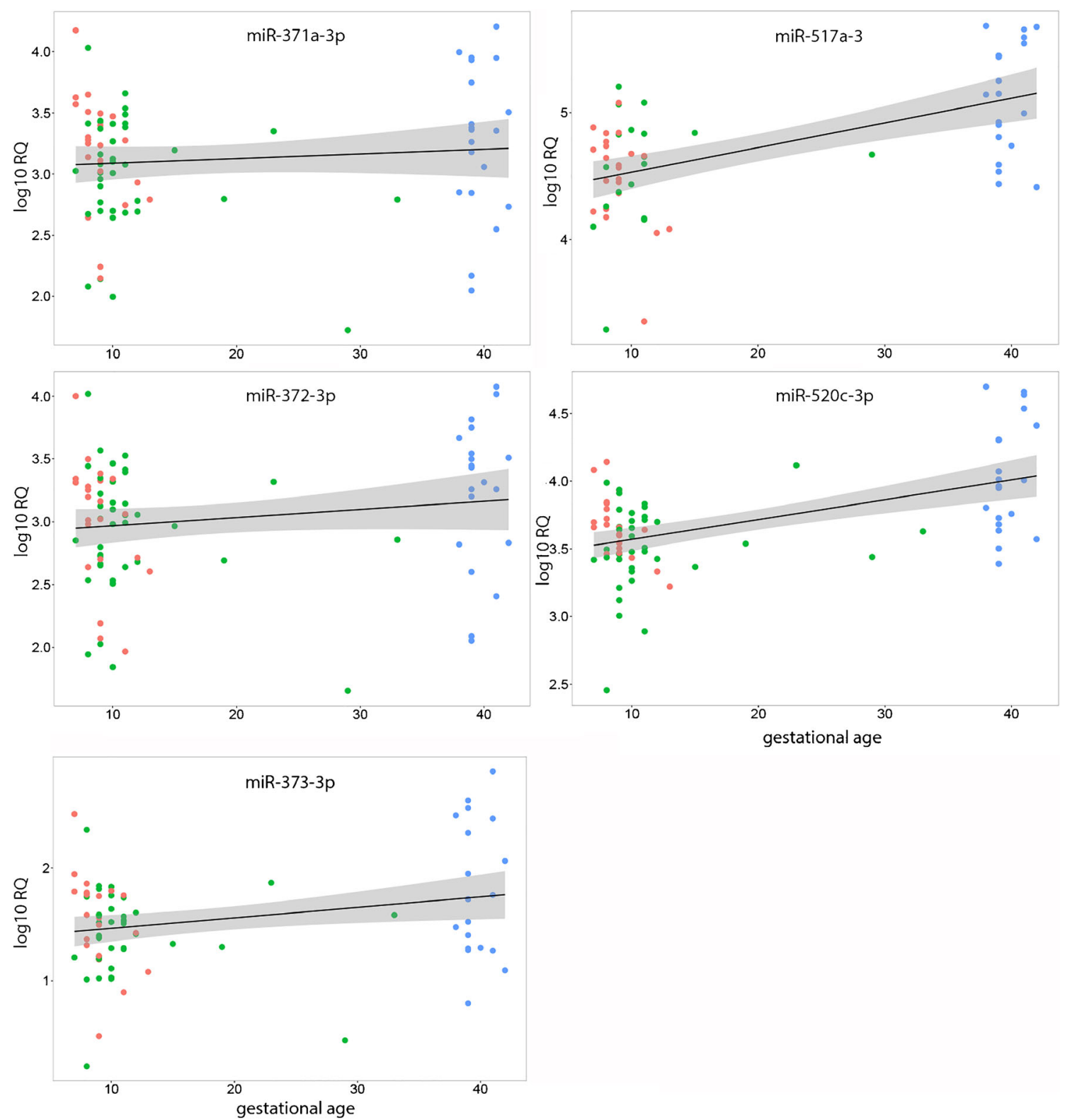

Fig. 2 Differences in the expression of placental tissue throughout pregnancy. Linear regression line with 95\% confidence range. Red dots, induced abortions; green dots, spontaneous abortions; blue dots, full-term placentas

Table 2 Expression levels of miRNAs in placental tissue of induced and first trimester spontaneous abortions

\begin{tabular}{lllllll}
\hline miRNA & AR & & & \multicolumn{2}{c}{ MSA (first trimester) } & \multirow{2}{*}{$p$ value } \\
\cline { 2 - 3 } & $n$ & Median RQ $\pm \mathrm{SD}$ & & $n$ & Median RQ $\pm \mathrm{SD}$ & \\
\hline $371 \mathrm{a}-3 \mathrm{p}$ & 22 & $1827 \pm 2981$ & & 33 & $1193 \pm 1925$ & 0.1734 \\
$372-3 \mathrm{p}$ & 22 & $1305 \pm 2000$ & & 33 & $1060 \pm 1855$ & 0.7015 \\
$373-3 \mathrm{p}$ & 22 & $37 \pm 59$ & & 33 & $32 \pm 37$ & 0.1963 \\
517a-3p & 22 & $337,610 \pm 26,530$ & & 19 & $38,240 \pm 44,192$ & 0.7814 \\
520c-3p & 21 & $4567 \pm 3008$ & 33 & $3131 \pm 2266$ & 0.1108 \\
\hline
\end{tabular}

Differences were analyzed by the Wilcoxon signed-rank test. A $p$ value of $<0.05$ was considered significant; a $p$ value of $<0.001$ was considered highly significant. $\mathrm{AR}=$ induced abortion, $\mathrm{MSA}=$ spontaneous abortion, $\mathrm{RQ}=$ relative quantification, $\mathrm{SD}=$ standard deviation
Analysis revealed that though expression differs within one placenta, it does not show relation to sampling site. Expression levels therefore seem to vary individually. This finding is partly in line with Wyatt et al. (2005) who found no association between placental sampling site and expression of some hypoxia-related genes (NDRG1, adipophilin, and human placental lactogen), whereas others were differently expressed. By investigating the placental transcriptome, Sood et al. (2006) found interindividual differences in the expression patterns of diverse genes as well.

The expression of $\mathrm{C} 19 \mathrm{MC}, \mathrm{C} 14 \mathrm{MC}$, and the miR-371-3 cluster was examined by Morales-Prieto et al. (2012) in first and third trimester trophoblast cells. The authors found a tenfold change in miR-520c and about 20 -fold increase in miR- 
517a. Our data confirm this finding, but the increase was lower. Since we investigated placental tissue instead of cell lines, our findings might mirror the in vivo situation more accurately. In concordance with Morales-Prieto et al. (2012), we did not find significant changes in the expression of miR-371-3 cluster throughout pregnancy. An increase of C19MC expression was also observed in the peripheral natural killer cells (NK) of pregnant women in the third compared with the first trimester (Ishida et al. 2015) with a rapid decline post-delivery (Ishida et al. 2015; Kambe et al. 2014). In contrast, Gu et al. (2013) observed a downregulation of miR-371-3 and miR-520c in the placental tissue of third compared with first trimester. We have no straightforward explanation but this conflicting data might partly be due to small sample size used in the latter study. Recently, an evidence for an aberrant expression of miRNAs of C19MC in the third trimester associated with preterm birth has been reported by Hromadnikova et al. (2017).

Xie et al. (2014) found higher expression of C19MC in villous trophoblasts than in extravillous trophoblast, suggesting a role in migration of extravillous trophoblast. The increasing expression in extravillous trophoblast results in the decreasing invasion. Since trophoblast invasion usually takes place during early pregnancy, but can be observed in second trimester pregnancies as well (Pijnenborg et al. 2008), increasing levels of C19MC might restrict invasion as pregnancy progresses and might therefore serve as protection against deep invasion of the trophoblast leading to placenta accreta. According to Umemura et al. (2013), trophoblastic cells of placenta accreta and especially of placenta increta and percreta show aggressive invasion into the myometrium. The authors found miR-34a, a miRNA inversely associated with invasiveness and metastasis, downregulated in placenta accreta. Regulation of trophoblast invasion is a complex process which is tightly regulated by an interaction of diverse factors (reviewed in Lash 2015). For example, the suppression of trophoblast invasion by $\beta$-1,4-galactosyltransferase III (B4GALT3) was investigated by Liao et al. (Liao et al. 2015). The authors showed an increased expression of B4GALT3 in third trimester extravillous trophoblasts implicating a role in invasion control. Nevertheless, the potential role of miRNAs of the C19MC cluster in the formation of placenta accreta remains to be elucidated.

A recent study revealed a different expression of miRNAs of the miR-371-3 cluster and C19MC cluster in women suffering from recurrent miscarriage (RM) (Wang et al. 2016). Our hypothesis when starting the study was that miR-371-3 and C19MC might play a role in miscarriage events, but we did not find significant differences in the expression of any of the miRNAs investigated between induced and spontaneous abortions. Wang et al. (2016) focused on women with RM and compared expression in the decidua and in villous trophoblasts. The authors found miR-517a-3p upregulated in the decidua, whereas miR-371a-5p and miR-372 were downregulated in the villi of RM patients compared with induced abortions of normal pregnancies. While the authors did exclude parental chromosomal alterations as a cause of RM, one might speculate if aberrant expression of these miRNAs, e.g., due to paternal deregulation can indicate a general problem of proper placenta development in these couples. From our data, this question cannot be answered because we do not know in which cases repeated abortions had occurred.

Moreover, since we investigated whole FFPE without microdissection and therefore cannot differentiate between the expression of decidua and villi, results might not be comparable. Furthermore, information about RM in our spontaneous abortion group was not available. Nevertheless, taken together, the miRNAs investigated in our study are not likely to play an important role in miscarriage events in general since we did not find significant differences in the expression of induced and spontaneous abortions.

Of note, as to the function of the miRNAs of both clusters, it has to be considered also that they do not only act in the cells where they are expressed but can also traffic between cells, thus exerting their effects in recipient cells. Accordingly, these miRNAs can be detected, e.g., in maternal and fetal venous plasma (Paquette et al. 2018). Luo et al. (2009) first found miRNAs of C19MC in exosomes released from trophoblast cells. Donker et al. (2012) showed that C19MC miRNAs are even predominantly present in these exosomes. These findings suggested a possible use in the monitoring of pregnancy. So far, studies have found that circulating miRNAs of C19MC can indeed serve as biomarkers in preeclampsia, fetal growth restriction, and hypertension (Higashijima et al. 2013; Hromadnikova et al. 2013; Hromadnikova et al. 2014; Kotlabova et al. 2011; Mouillet et al. 2010). Compared with the broad range in the expression of all miRNAs investigated in placental FFPE, individual variation in maternal serum was still high, but nevertheless half as broad. Of note, however, the data presented here is restricted to very few cases and further investigations are required. In the literature, diverse results concerning the correlation of miRNA levels in the placenta and serum have been reported. Higashijima et al. (2013) found different expressions of C19MC miRNAs in the placentas of fetal growth restriction (FGR) compared with normal pregnancies but no differences in serum levels between these groups. On the other hand, Mouillet et al. (2010) found an inverse correlation of placental and serum miRNA levels in FGR pregnancies. Williams et al. (2013) investigated placental tissue and plasma probes of mother-child pairs. Some miRNAs of C19MC were more abundant in maternal and fetal plasma than in the corresponding placenta, and some showed reverse values and others, e.g., miR-517a were highly expressed in the placenta and plasma of both the mother and fetus. However, heterogeneity of serum concentration correlated with the corresponding placenta samples in Williams' data. 
While for the miRNAs of C19MC tested the expression increased with increasing gestational age, the present study revealed strong interindividual differences in the expression of the miR-371-3 cluster in the placental tissue. Differences were also seen for the miRNAs of the C19MC cluster tested, but the levels differed to a much lesser extent than for the former microRNA. As a straightforward explanation, differences related to the site of the placenta where the sample has been taken from were excluded. From our data, these differences do not in general seem to be related to first trimester abortion but it remains to be elucidated whether or not they affect other fundamental processes during prenatal life.

Acknowledgements Open Access funding provided by Projekt DEAL.

Author contribution IF, AG, JB, and ML conceived and designed the study. $\mathrm{AG}, \mathrm{IF}, \mathrm{LB}$, and MS performed the research.

$\mathrm{RN}, \mathrm{AG}, \mathrm{MS}$, and JB analyzed the data.

$\mathrm{BH}, \mathrm{ML}$, and SF provided clinical material and carried out clinical workout.

BH performed the pathological analysis.

$\mathrm{AG}$ and JB wrote the article.

All authors have read and approved the final version of the manuscript.

Funding There was no external funding for this study.

\section{Compliance with ethical standards}

All samples of induced and spontaneous abortions investigated were initially taken for diagnostic purposes. Samples were de-identified before their use following the rules of the Helsinki declaration. All full-term placentas and serum samples were collected after a written informed consent was given by the mother. The study was approved by the local ethics committee (Ärztekammer Bremen, reference number 330).

Conflict of interest The authors declare competing financial interests because J.B. is an applicant and I.F. and J.B. are named inventors of a patent application (WO2013079701 A2) claiming the use of C19MC miRNAs for immunomodulation.

Open Access This article is licensed under a Creative Commons Attribution 4.0 International License, which permits use, sharing, adaptation, distribution and reproduction in any medium or format, as long as you give appropriate credit to the original author(s) and the source, provide a link to the Creative Commons licence, and indicate if changes were made. The images or other third party material in this article are included in the article's Creative Commons licence, unless indicated otherwise in a credit line to the material. If material is not included in the article's Creative Commons licence and your intended use is not permitted by statutory regulation or exceeds the permitted use, you will need to obtain permission directly from the copyright holder. To view a copy of this licence, visit http://creativecommons.org/licenses/by/4.0/.

\section{References}

Anton L, Olarerin-George AO, Hogenesch JB, Elovitz MA (2015) Placental expression of miR-517a/b and miR-517c contributes to trophoblast dysfunction and preeclampsia. PLoS One 10:e122707
Bentwich I, Einat P, Aharonov R, Spector Y, Einav U, Bentwich Z, Barzilai A, Meiri E, Barad O, Gilad S, Sharon E, Avniel A, Karov Y (2005) Identification of hundreds of conserved and nonconserved human microRNAs. Nat Genet 37:766-770. https://doi.org/10. 1038/ng1590

Bortolin-Cavaillé M, Dance M, Weber M, Cavaillé J (2009) C19MC microRNAs are processed from introns of large Pol-II, nonprotein-coding transcripts. Nucl Acids Res 37:3464-3473. https:// doi.org/10.1093/nar/gkp205

Bullerdiek J, Flor I (2012) Exosome-delivered microRNAs of "chromosome 19 microRNA cluster" as immunomodulators in pregnancy and tumorigenesis 5:27

Delorme-Axford E, Donker RB, Mouillet JF, Chu T, Bayer A, Ouyang Y, Wang T, Stolz DB, Sarkar SN, Morelli AE, Sadovsky Y, Coyne CB (2013) Human placental trophoblasts confer viral resistance to recipient cells. Proc Natl Acad Sci U S A 110:12048-12053

Ding J, Huang F, Wu G, Han T, Xu F, Weng D, Wu C, Zhang X, Yao Y, Zhu X (2015) MiR-519d-3p suppresses invasion and migration of trophoblast cells via targeting MMP-2. PLoS One 10:e120321

Donker RB, Mouillet JF, Chu T, Hubel CA, Stolz DB, Morelli AE, Sadovsky Y (2012) The expression profile of C19MC microRNAs in primary human trophoblast cells and exosomes. Mol Hum Reprod 18:417-424. https://doi.org/10.1093/molehr/gas013

Flor I, Neumann A, Freter C, Helmke BM, Langenbuch M, Rippe V, Bullerdiek J (2012) Abundant expression and hemimethylation of C19MC in cell cultures from placenta-derived stromal cells. Biochem Biophys Res Commun 422:411-416

Gillis AJ, Rijlaarsdam MA, Eini R, Dorssers LC, Biermann K, Murray MJ, Nicholson JC, Coleman N, Dieckmann KP, Belge G, Bullerdiek J, Xu T, Bernard N, Looijenga LH (2013) Targeted serum miRNA (TSmiR) test for diagnosis and follow-up of (testicular) germ cell cancer patients: a proof of principle. Mol Oncol 7:1083-1092

Gu Y, Sun J, Groome LJ, Wang Y (2013) Differential miRNA expression profiles between the first and third trimester human placentas. Am J Physiol Endocrinol Metab 304:836

Higashijima A, Miura K, Mishima H, Kinoshita A, Jo O, Abe S, Hasegawa Y, Miura S, Yamasaki K, Yoshida A, Yoshiura K, Masuzaki H (2013) Characterization of placenta-specific microRNAs in fetal growth restriction pregnancy. Prenat Diagn 33:214-222

Hromadnikova I, Kotlabova K, Ondrackova M, Kestlerova A, Novotna V, Hympanova L, Doucha J, Krofta L (2013) Circulating C19MC microRNAs in preeclampsia, gestational hypertension, and fetal growth restriction. Mediat Inflamm 2013:186041

Hromadnikova I, Kotlabova K, Hympanova L, Doucha J, Krofta L (2014) First trimester screening of circulating C19MC microRNAs can predict subsequent onset of gestational hypertension. PLoS One 9:e113735

Hromadnikova I, Kotlabova K, Ivankova K, Krofta L (2017) Expression profile of C19MC microRNAs in placental tissue of patients with preterm prelabor rupture of membranes and spontaneous preterm birth. Mol Med Rep 16:3849-3862. https://doi.org/10.3892/mmr. 2017.7067

Ishida Y, Zhao D, Ohkuchi A, Kuwata T, Yoshitake H, Yuge K, Takizawa T, Matsubara S, Suzuki M, Saito S, Takizawa T (2015) Maternal peripheral blood natural killer cells incorporate placentaassociated microRNAs during pregnancy. Int J Mol Med 35:15111524

Kambe S, Yoshitake H, Yuge K, Ishida Y, Ali MM, Takizawa T, Kuwata T, Ohkuchi A, Matsubara S, Suzuki M, Takeshita T, Saito S, Takizawa T (2014) Human exosomal placenta-associated miR517a-3p modulates the expression of PRKG1 mRNA in Jurkat cells. Biol Reprod 91:129

Kim H, Lee G, Ganat Y, Papapetrou EP, Lipchina I, Socci ND, Sadelain M, Studer L (2011) miR-371-3 expression predicts neural 
differentiation propensity in human pluripotent stem cells. Cell Stem Cell 8:695-706

Kotlabova K, Doucha J, Hromadnikova I (2011) Placental-specific microRNA in maternal circulation-identification of appropriate pregnancy-associated microRNAs with diagnostic potential. J Reprod Immunol 89:185-191

Langroudi L, Jamshidi-Adegani F, Shafiee A, Rad SM, Keramati F, Azadmanesh K, Arefian E, Soleimani M (2015) MiR-371-373 cluster acts as a tumor-suppressor-miR and promotes cell cycle arrest in unrestricted somatic stem cells. Tumour Biol 36:7765-7774

Lash GE (2015) Molecular cross-talk at the feto-maternal interface. Cold Spring Harb Perspect Med 5. https://doi.org/10.1101/cshperspect. a023010

Liao WC, Liu CH, Chen CH, Hsu WM, Liao YY, Chang HM, Lan CT, Huang MC, Shyu MK (2015) Beta-1,4-galactosyltransferase III suppresses extravillous trophoblast invasion through modifying beta1integrin glycosylation. Placenta 36:357-364

Livak KJ, Schmittgen TD (2001) Analysis of relative gene expression data using real-time quantitative PCR and the 2(-Delta Delta C(T)). Methods 25:402-408

Luo SS, Ishibashi O, Ishikawa G, Ishikawa T, Katayama A, Mishima T, Takizawa T, Shigihara T, Goto T, Izumi A, Ohkuchi A, Matsubara S, Takeshita T, Takizawa T (2009) Human villous trophoblasts express and secrete placenta-specific microRNAs into maternal circulation via exosomes. Biol Reprod 81:717-729

Malnou EC, Umlauf D, Mouysset M, Cavaille J (2019) Imprinted MicroRNA Gene Clusters in the Evolution, Development, and Functions of Mammalian Placenta. Front Genet 9:706. https://doi. org/10.3389/fgene.2018.00706

miRBase (2014) http://www.mirbase.org; release 21, data accessed 2505-2016

Morales-Prieto DM, Chaiwangyen W, Ospina-Prieto S, Schneider U, Herrmann J, Gruhn B, Markert UR (2012) MicroRNA expression profiles of trophoblastic cells Placenta 33:725-734

Mouillet JF, Chu T, Hubel CA, Nelson DM, Parks WT, Sadovsky Y (2010) The levels of hypoxia-regulated microRNAs in plasma of pregnant women with fetal growth restriction. Placenta 31:781-784

Mouillet JF, Ouyang Y, Coyne CB, Sadovsky Y (2015) MicroRNAs in placental health and disease. Am J Obstet Gynecol 213:163

Noack F, Ribbat-Idel J, Thorns C, Chiriac A, Axt-Fliedner R, Diedrich K, Feller AC (2011) miRNA expression profiling in formalin-fixed and paraffin-embedded placental tissue samples from pregnancies with severe preeclampsia. J Perinat Med 39:267-271

Paquette AG, Chu T, Wu X, Wang K, Price ND, Sadovsky Y (2018) Distinct communication patterns of trophoblastic miRNA among the maternal-placental-fetal compartments. Placenta 72-73:28-35. https://doi.org/10.1016/j.placenta.2018.10.004
Pijnenborg R, Vercruysse L, Hanssens M (2008) Fetal-maternal conflict, trophoblast invasion, preeclampsia, and the red queen. Hypertens Pregnancy 27:183-196

R Core Team (2015) R: A language and environment for statistical computing. R Foundation for Statistical Computing, Vienna, Austria; 2015 [http://www.R-projekt.org/], date accessed 27-01-2017

Rippe V, Dittberner L, Lorenz VN, Drieschner N, Nimzyk R, Sendt W, Junker K, Belge G, Bullerdiek J (2010) The two stem cell microRNA gene clusters C19MC and miR-371-3 are activated by specific chromosomal rearrangements in a subgroup of thyroid adenomas. PLoS One 5:e9485

Rosenbluth EM, Shelton DN, Wells LM, Sparks AE, Van Voorhis BJ (2014) Human embryos secrete microRNAs into culture media-a potential biomarker for implantation. Fertil Steril 101:1493-1500

Schmidt JK, Block LN, Golos TG (2018) Defining the rhesus macaque placental miRNAome: Conservation of expression of placental miRNA clusters between the macaque and human. Placenta 65 : 55-64. https://doi.org/10.1016/j.placenta.2018.04.003

Sood R, Zehnder JL, Druzin ML, Brown PO (2006) Gene expression patterns in human placenta. Proc Natl Acad Sci U S A 103:54785483

Strub GM, Kirsh AL, Whipple ME, Kuo WP, Keller RB, Kapur RP, Majesky MW, Perkins JA (2016) Endothelial and circulating C19MC microRNAs are biomarkers of infantile hemangioma. JCI Insight 1:e88856. https://doi.org/10.1172/jci.insight.88856

Umemura K, Ishioka S, Endo T, Ezaka Y, Takahashi M, Saito T (2013) Roles of microRNA-34a in the pathogenesis of placenta accreta. J Obstet Gynaecol Res 39:67-74

Wang JM, Gu Y, Zhang Y, Yang Q, Zhang X, Yin L, Wang J (2016) Deep-sequencing identification of differentially expressed miRNAs in decidua and villus of recurrent miscarriage patients. Arch Gynecol Obstet 17:2570-2580

Williams JL, Gatson NN, Smith KM, Almad A, McTigue DM, Whitacre CC (2013) Serum exosomes in pregnancy-associated immune modulation and neuroprotection during CNS autoimmunity. Clin Immunol 149:236-243

Wyatt SM, Kraus FT, Roh CR, Elchalal U, Nelson DM, Sadovsky Y (2005) The correlation between sampling site and gene expression in the term human placenta. Placenta 26:372-379

Xie L, Mouillet JF, Chu T, Parks WT, Sadovsky E, Knofler M, Sadovsky Y (2014) C19MC microRNAs regulate the migration of human trophoblasts. Endocrinology 155:4975-4985

Zhang R, Wang YQ, Su B (2008) Molecular evolution of a primatespecific microRNA family. Mol Biol Evol 25:1493-1502

Publisher's note Springer Nature remains neutral with regard to jurisdictional claims in published maps and institutional affiliations. 